\title{
DEVIR-VEGETAL: EXPERIMENTAÇÕES COM UM CORPO - PLANTA - ESCRITA
}

\author{
BECOMING-PLANT: EXPIREMENTS WITH A BODY - PLANT - WRITING \\ Gabriela de Sousa Tóffoli ${ }^{1}$ \\ Kátia Maria Kasper ${ }^{2}$
}

Resumo: Este texto traz um recorte dos processos de uma pesquisa de mestrado concluída em 2019, envolvendo a cartografia (ROLNIK, 2007) de hortas urbanas em Curitiba e a criação de modos de vida minoritários. Composições com um corpo planta que se decompõe a todo momento parecendo desvelar um flerte e abrir à criação deste inventário botânico afetivo. Fotossintetizar. Alterar formatos, bricolar. Aproximar-se dos modos de existência vegetal, numa experimentação de escrita convocando saberes outros que vêm habitar um desejo de escrita vegetal, inumana. Permeável. Disponível. E no ato de instaurar, fazer ver, autorizar existências que estão em potência de criação (LAPOUJADE, 2017). Interessam os processos de diferenciação em movimento molecular. Experimentações de estados vegetativos de escrita. Tempos vegetais. Microrganismos tomando conta de um corpo-planta-escrita e imprimindo os tons de cinza amarronado, pontos brancos e bolor.

Palavras-chave: Vegetal; corpo; escrita.

\begin{abstract}
This text presents an outline of the processes of a master's research completed in 2019, involving the cartography (ROLNIK, 2007) of urban vegetables gardens in Curitiba and the creation of minority ways of life. Compositions with a plant body that decomposes all the time seeming to reveal a flirtation and open itself to the creation of this affective botanical inventory. Photosynthesize. Change formats, DIY. Approaching the modes of plant existence, in a writing experiment, summoning other knowledge that comes to inhabit a desire for vegetal, inhuman writing. Permeable. Available. And in the act of establishing, making visible, authorizing existences that are in the power of creation (LAPOUJADE, 2017). Interest the processes of differentiation in molecular movement. Experiments of vegetative state's writing. Vegetable times. Microorganisms taking care of a body-plant-writing and printing the shades of brownish gray, white dots and mold.
\end{abstract}

Keywords: Vegetable; body; writing.

\footnotetext{
${ }^{1}$ UFPR. E-mail: gabrielatoffoli@gmail.com.
}

${ }^{2}$ UFPR.E-mail: katiakasper@uol.com.br. 
DEVIR-VEGETAL: EXPERIMENTAÇÕES COM UM CORPO - PLANTA - ESCRITA

\section{INVENTÁRIO BOTÂNICO AFETIVO}

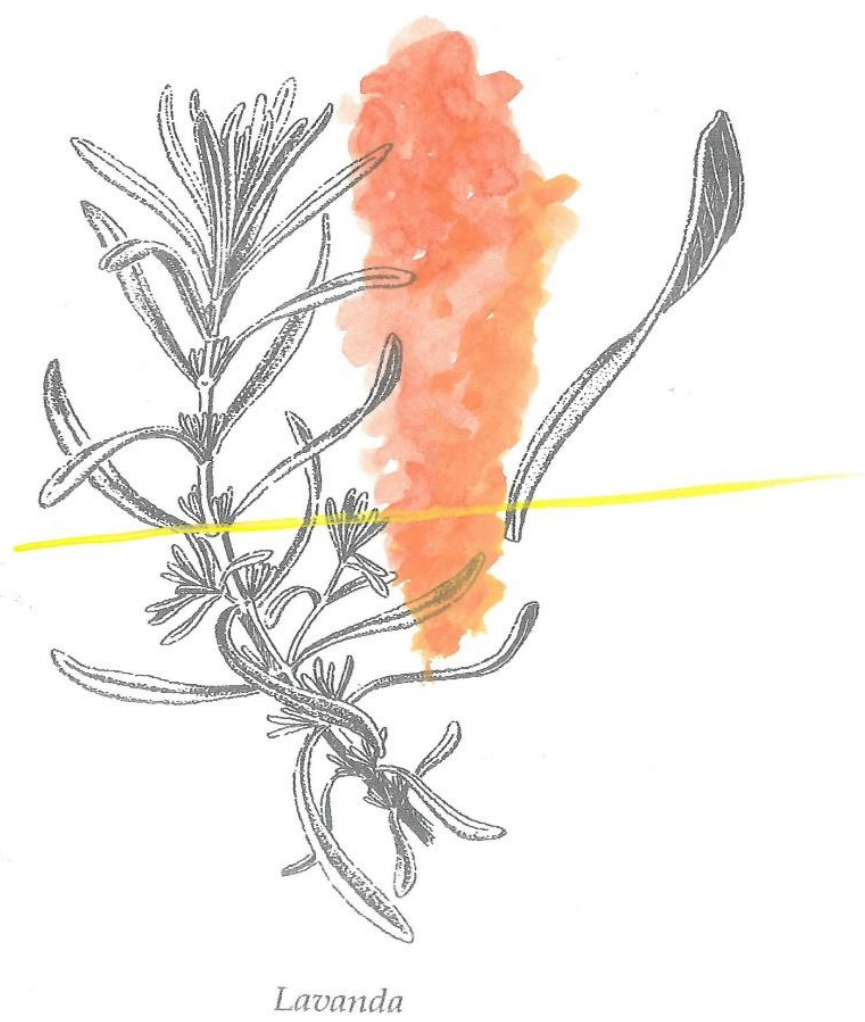

Lavanda

A força e a fluidez de uma onda 


\section{Malva}

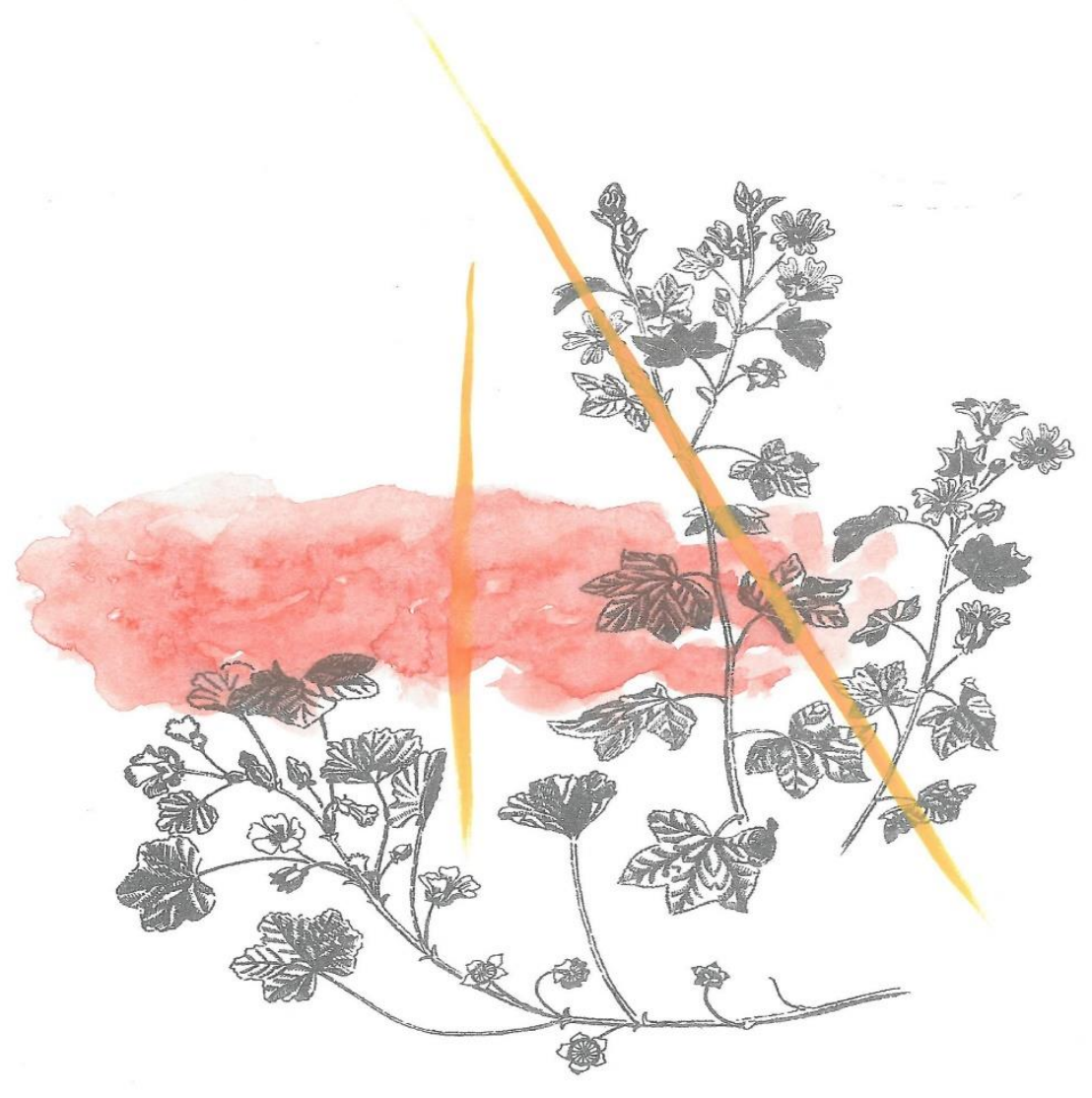

Malvas

Ela se punha a correr alguns quilômetros quando aquela coisa a arrebatava, um vai e vem do estômago ao peito

Só-corria

vai e vem vai e vem vai e vem vai e vem vai e vem vai e vem vai e vem vai e vem vai e vem vai e vem vai e vem vai e vem vai e vem vai e vem vai e vem vai e vem vai e vem vai e vem vai e vem vai e vem vai e vem vai e vem vai e vem vai e vem vai e vem vai e vem vai e vem vai e vem vai e vem vai e vem 
vai e vem vai e vem vai e vem vai e vem vai e vem vai e vem vai e vem vai e vem vai e vem vai e vem vai e vem vai e vem vai e vem vai e vem vai e vem vai e vem vai e vem vai e vem vai e vem vai e vem vai e vem vai e vem vai e vem vai e vem vai e vem vai e vem vai e vem vai e vem vai e vem vai e vem vai e vem vai e vem vai e vem vai e vem vai e vem vai e vem vai e vem vai e vem vai e vem vai e vem vai e vem vai e vem vai e vem vai e vem vai e vem vai e vem vai e vem vai e vem vai e vem vai e vem vai e vem vai e vem vai e vem vai e vem vai e vem vai e vem vai e vem vai e vem vai e vem vai e vem vai e vem vai

vem vai e vem vai e vem vai e vem vai e vem e vai e vem e vai vai e vem vai e vem vai e vem vai e vem vai e vem vai e vem vai e vem vai e vem vai e vem vai e vem vai e vem vai e vem vai e vem vai e vem vai e vem vai e vem vai e vem vai e vem vai e vem vai e vem vai e vem vai e vem vai e vem vai e vem vai e vem vai e vem vai e vem vai e vem vai e vem vai e vem vai e vem vai e vem vai e vem vai e vem vai e vem vai e vem vai e vem vai e vem vai e vem vai e vem vai e vem vai e vem vai e vem vai e vem vai e vem vai e vem vai e vem vai e vem vai e vem vai e vem vai e vem vai e vem vai e vem vai e vem vai e vem vai e vem vai e vem vai e vem vai e vem vai e vem vai e vem vai e vem vai e vem vai e vem vai e vem vai e vem vai e vem vai e vem vai e vem vai e vem vai e vem vai e vem vai e vem vai e vem vai e vem vai e vem vai e vem vai e vem vai e vem vai e vem vai e vem vai e vem vai e vem vai e vem vai e vem vai e vem vai e vem vai e vem vai e vem vai e vem vai e vem vai e vem vai e vem vai e vem vai e vem vai e vem vai e vem vai e vem vai e vem vai e vem vai e vem vai e vem vai e vem vai e vem vai e vem vai e vem vai vem vai e vem vai e vem vai e vem vai e vem 


\section{Losna}

Era virada em estrelas. As vezes sentia que sua pele se confundia com aqueles pontos refletidos. Mesclada com o céu mantinha-se parada, estática, respiração controlada pra não balançar. Os pés enraizavam o chão à espera do vento. Era um dia quente e nenhuma brisa alcançava nenhum pêlo.
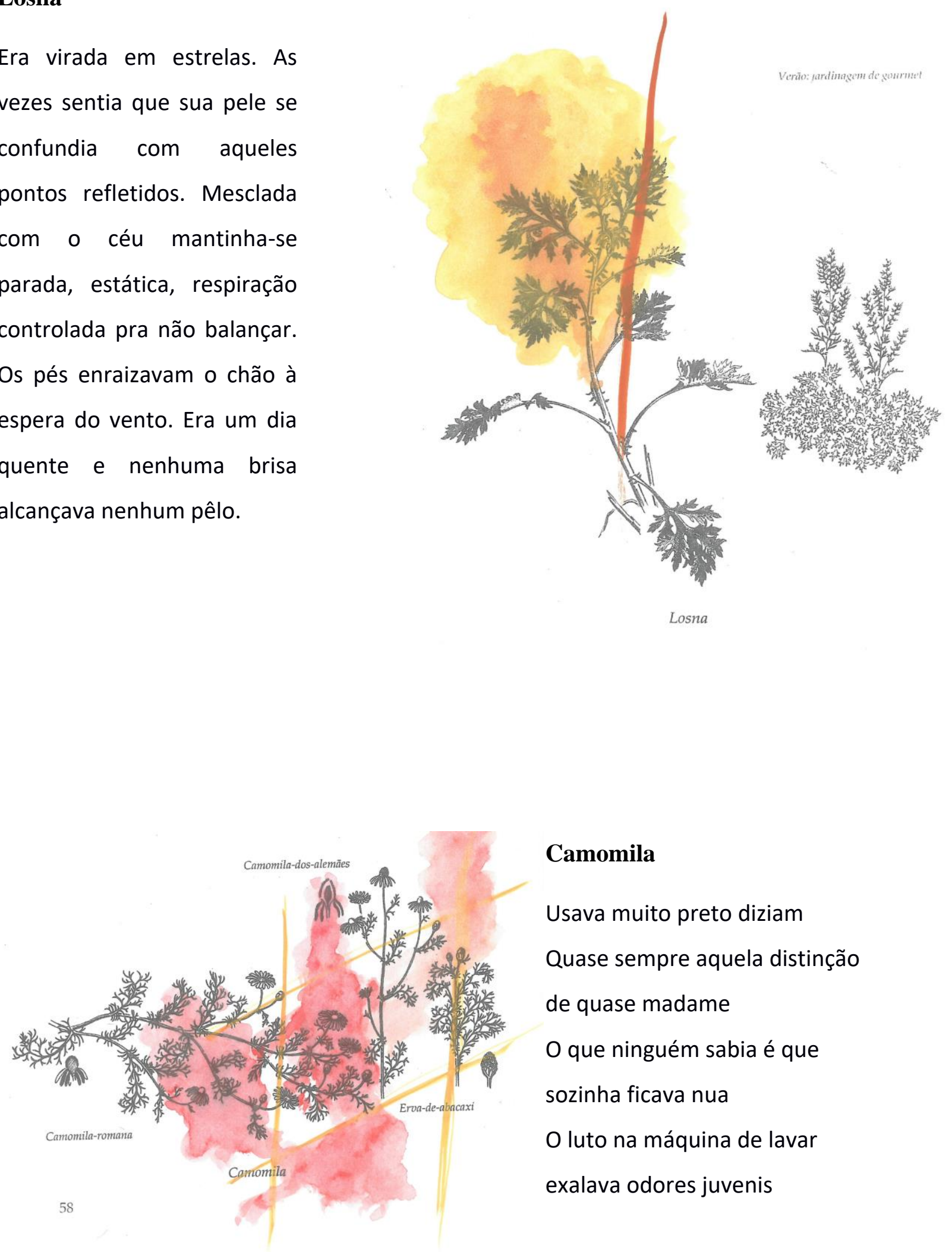

\section{Camomila}

Usava muito preto diziam

Quase sempre aquela distinção de quase madame

$O$ que ninguém sabia é que sozinha ficava nua O luto na máquina de lavar exalava odores juvenis 


\section{Urtiga}

Pra que serviam os pés

pensava?

mais atrapalha do que ajuda

Tropeçando viveria mais perto do chão?

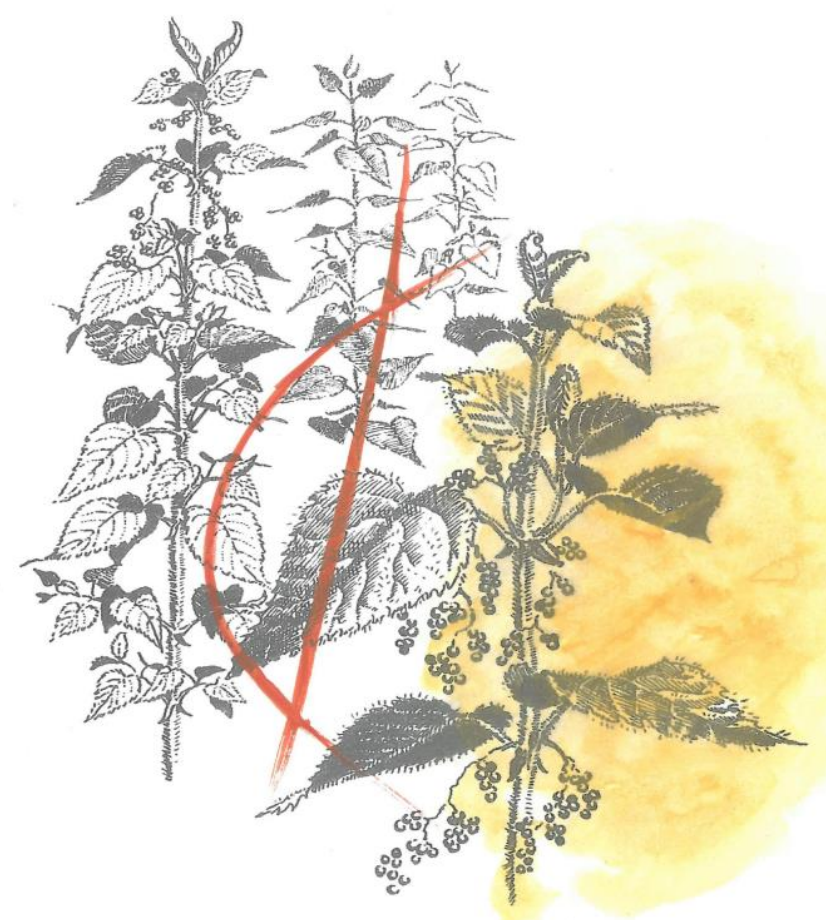

Urtiga

\section{Mirra}

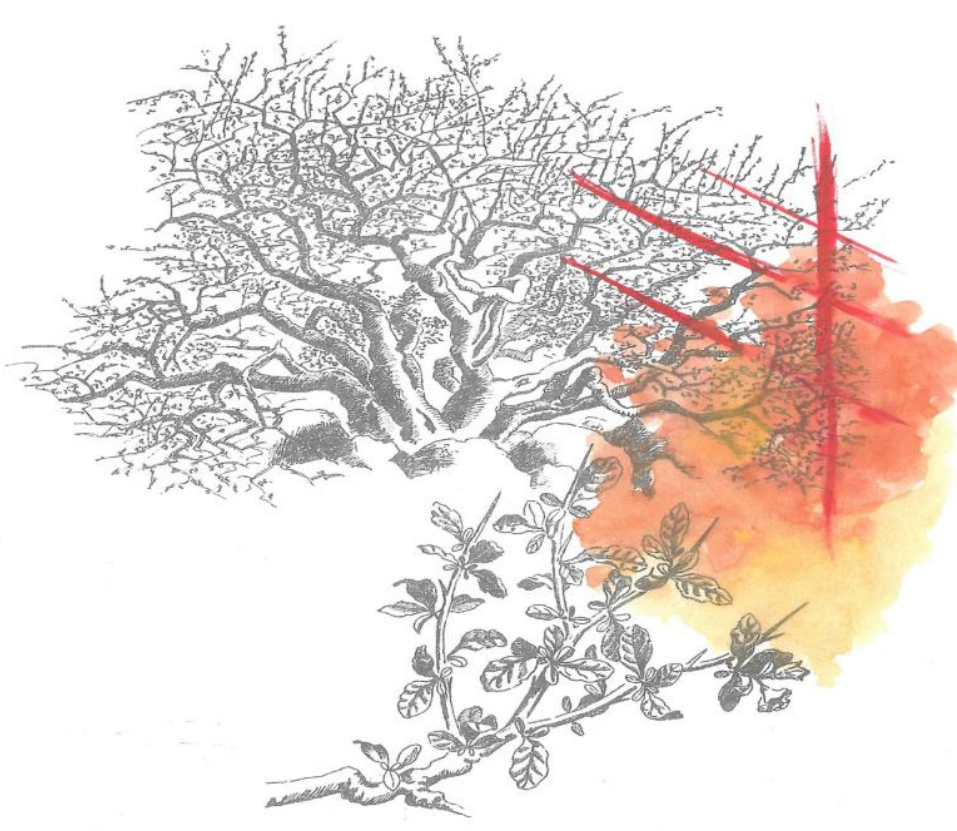

Tinha uma amiga

quando criança

ela quase lembrava o

nome

Distraída

sua filha descalça

dançava na mesa da

sala 


\section{Valeriana}

Nos sábados colocava a mesma música

Usava panos de prato no chão

Cozinhava a mesma lasanha

Acabava sozinha com o vinho

dormia

limpa
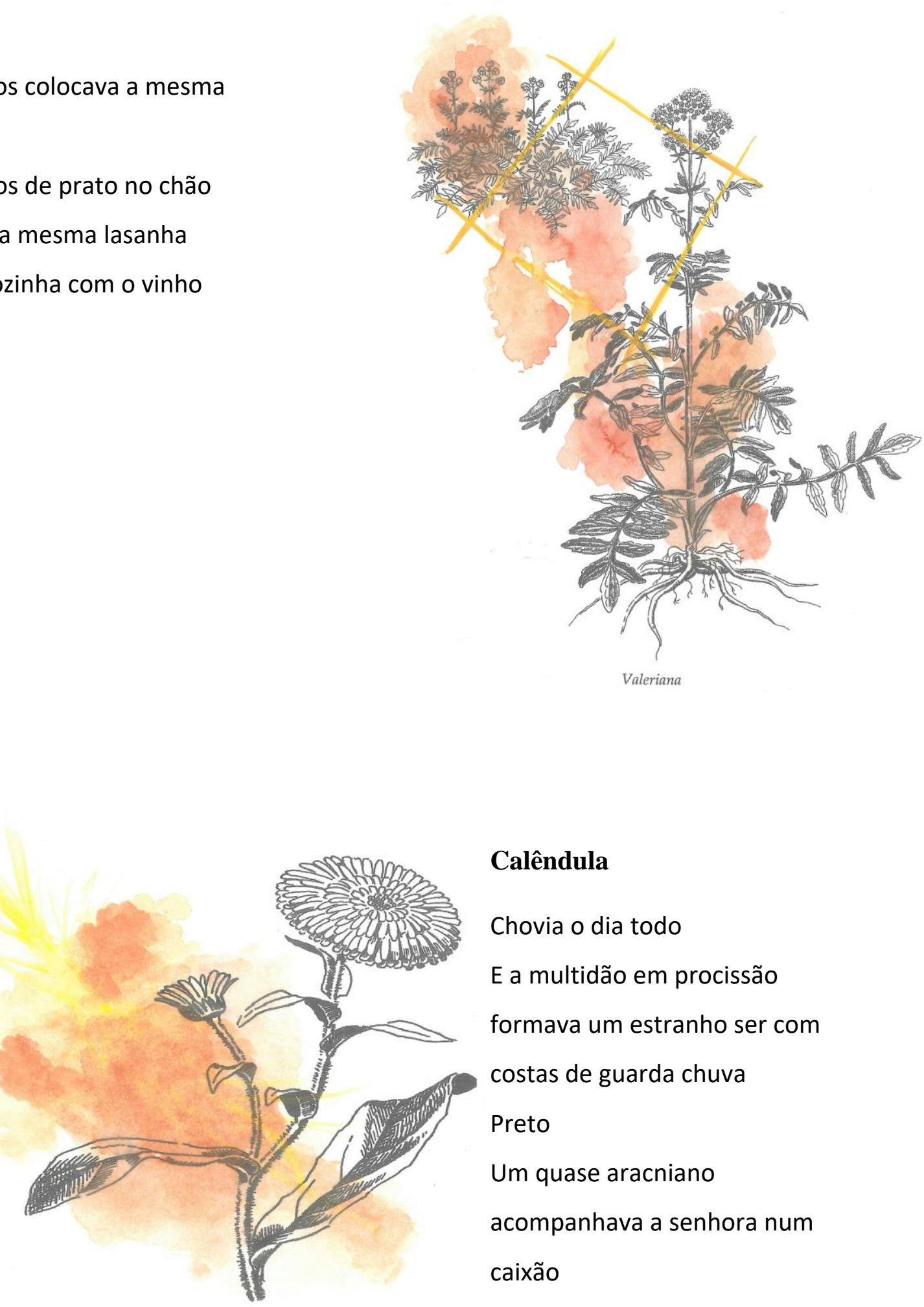

Calêndula

Chovia o dia todo

E a multidão em procissão

formava um estranho ser com

costas de guarda chuva

Preto

Um quase aracniano

acompanhava a senhora num

caixão

Calêndula 


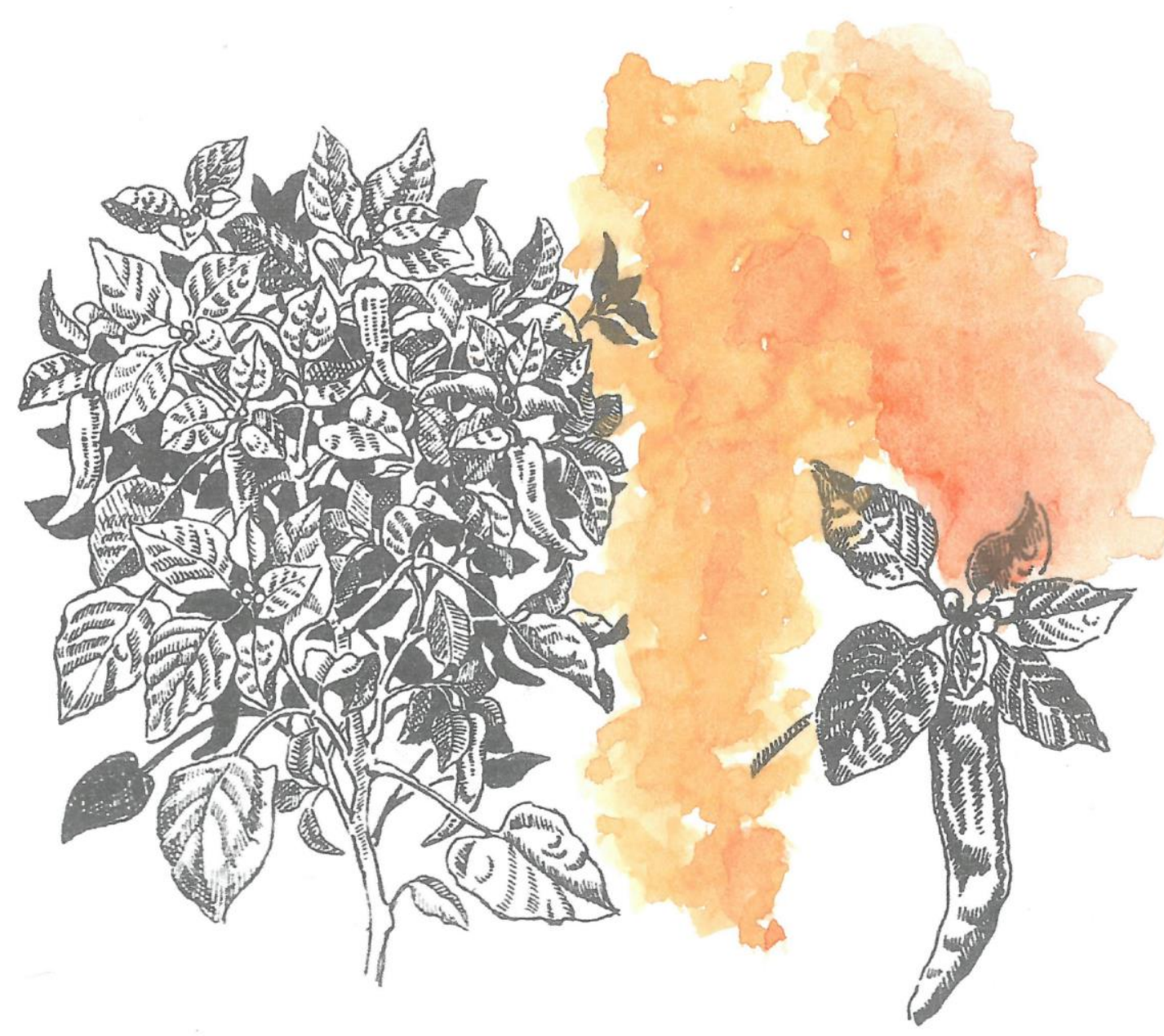

Pimenta-de-caiena

\section{Pimenta de caiena}

Abria-se em pétalas

daquelas flores de cactos que na noite se escondem

Se recolhendo no mistério 


\section{Cavalinha}

cavalos".

Meia perna dentro, meia fora, meias nove fora, uma brincadeira

Água em pingos grossos, arranha a pele

E escorre em tosco rio inventado

Mãos para fora, protegendo uma escrita seca de corpo molhado

Anfíbio esse lugar

Ela não obedece a gravidade sobe e toma todo o corpo

folhas e a tinta

manchas

encharcada inspiração

escorre

ir pingando até não sobrar mais

nada

algumas guelras e respirar no fundo

quem sabe

um mar surge pelas pernas

caldos, caldos, caldos

água no nariz, espirros

respiro

respiro

respiro

guelras

Altemar Dutra no rádio

A metamorfose segue

O que separa e o que invade?

Impermeáveis 
Você merece essa fome

Raízes emergem das veias do pé

Os braços se movimentam delicados

Com receio de quebrar as novas radículas

A coluna dói

De um rasgo na pele emergem brotos

É primavera afinal

Tomates a chuchus

Bromélias a margaridas

Costelas de adão

Sem permissão

a cada vértebra surjo verde

É preciso rasgar a pele

Você merece essa fo

Banhos botânicos 


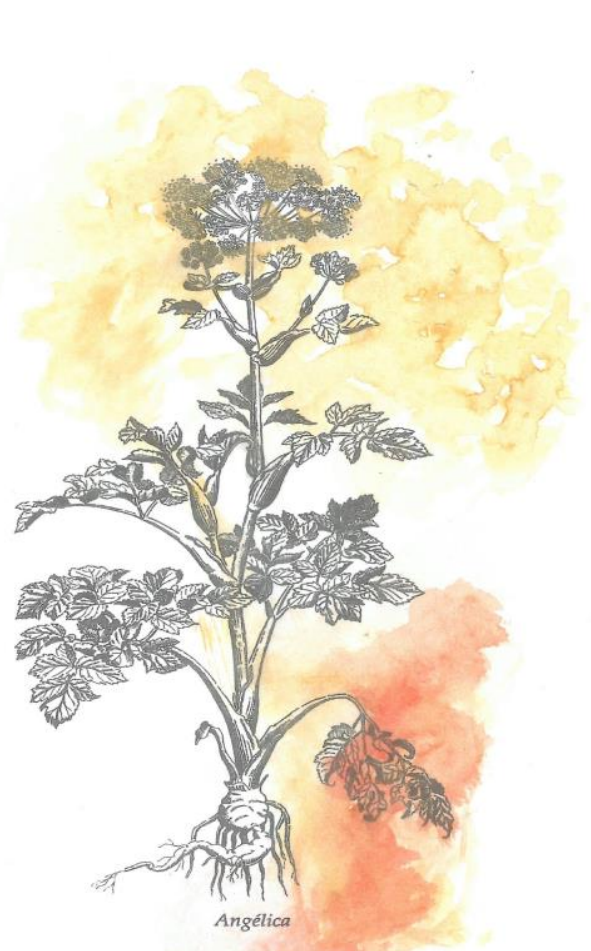

\section{Angélica}

Ela gostava da janela Quando escrevia, juntava a poltrona ficando com os joelhos abaixo do parapeito.

O caderno no colo fazia suar as coxas. Orvalho.

Era tudo sobre água, no fim.

Tinha um horizonte dividido em cenas e planos. Escrevia morta de medo da distinção exploratória. Da totalização dos seus horizontes e sensações Os tomates ao longe exibiam sua madures.

Saiu correndo Para inspiração

A insônia viria dos tomates, ela previa. 


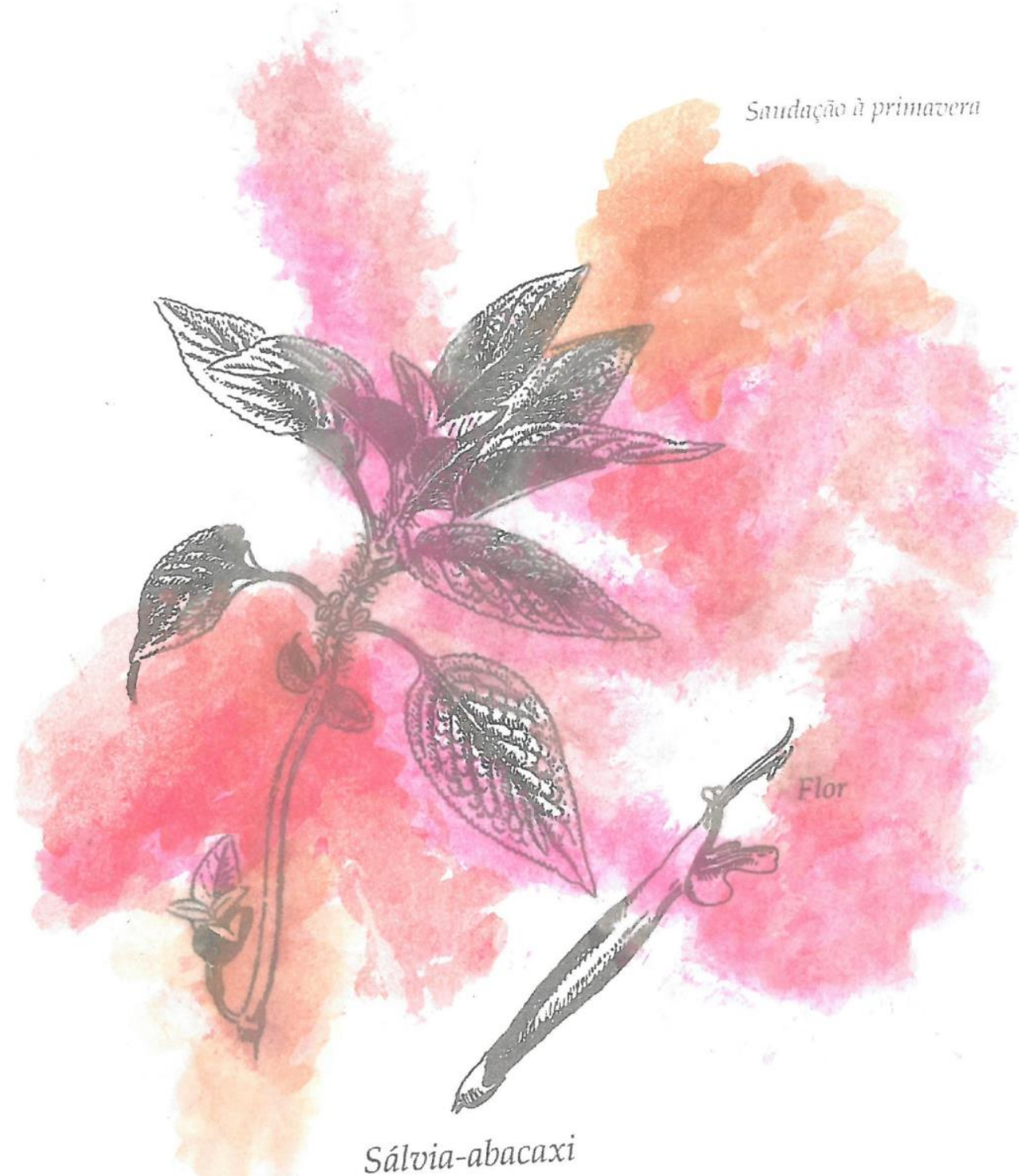

\section{Sálvia}

Às vezes experimentava coisas estranhas

Deitava no tapete e fechava olhos e ouvidos

Seu coração fazia tanto barulho que ela despertava do sono vegetal

Como é que o mar acolhe os rios que chegam depois de um grande percurso, ein? 


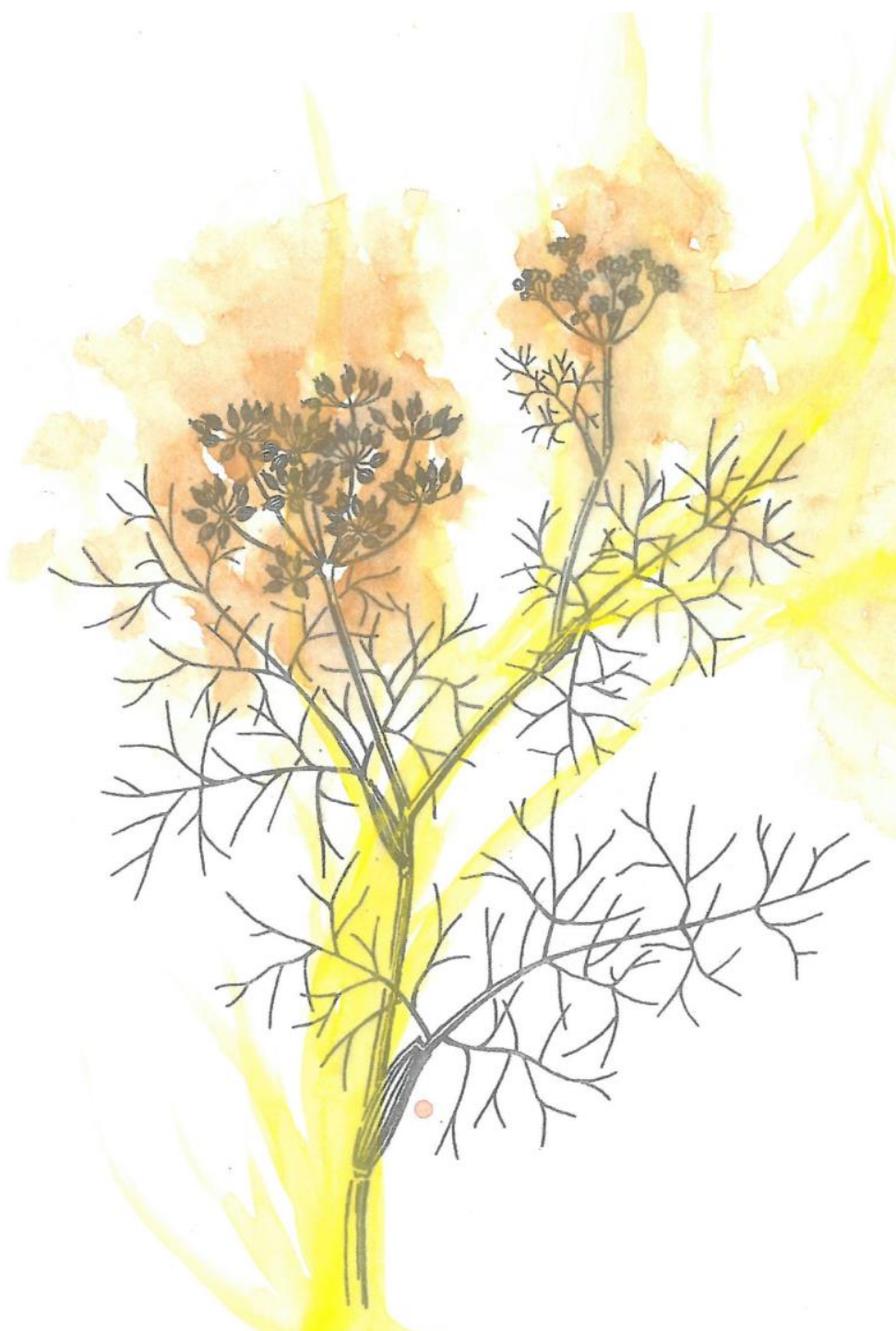

\section{Erva-doce}

\section{Erva doce}

Desde menina fazia suas próprias vassouras de piaçava. Sua mãe chamava a pobre planta de vai-tudo. la até o caule e puxava as fibras que iam soltando. Amarravam as pequenas vassourinhas e depois tudo junto virava um grande feito.

A fibra era a que melhor varria as folhas secas na varanda Vai ver é porquê elas já se conheciam. 


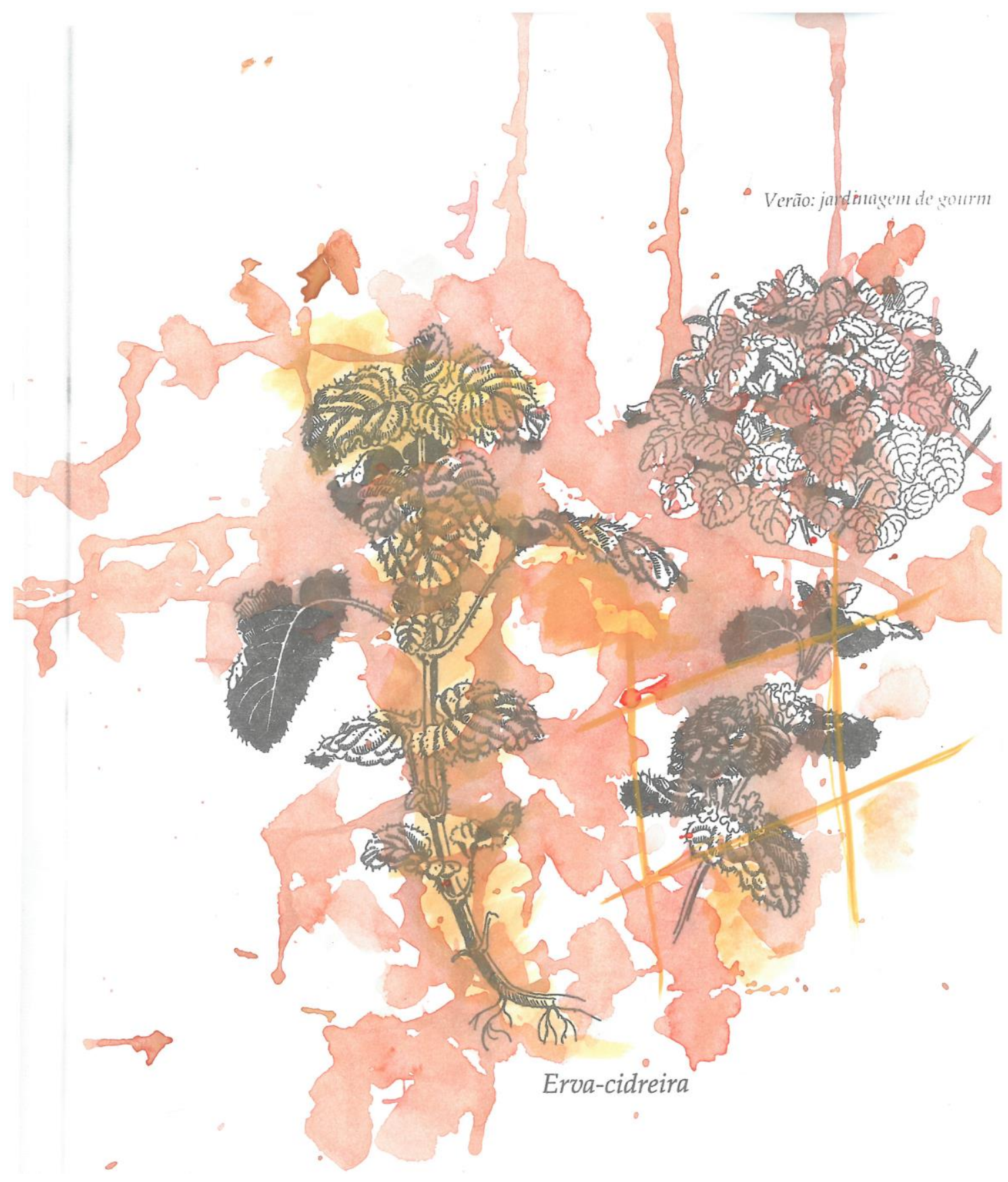

\section{Erva cidreira}

Como é que pode

numa só existência

um tanto de mundo? 


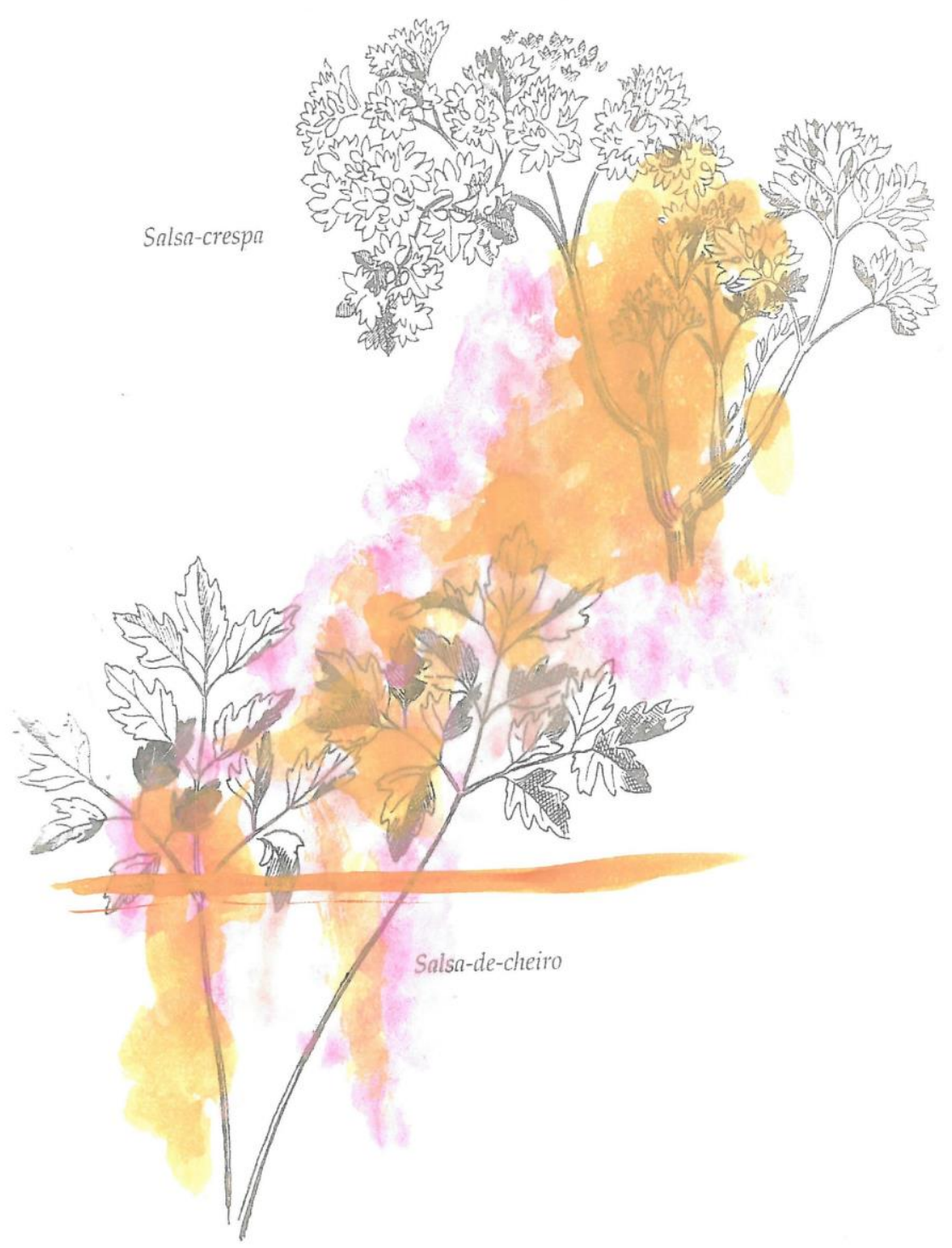

\section{Salsa}

O gato de estimação morreu quando ela tinha uns 8 pra 9 anos. O pai denunciava no olhar uma preocupação com a pobre menina.

Sugeriu um ritual.

Enterrariam o bichano no quintal e plantariam uma árvore no lugar.

Não sei bem precisar, mas todos os meses, durante um bom tempo ela levava novelos de lã e enrolava nos galhos, deixando um pedacinho solto pra balançar no vento 


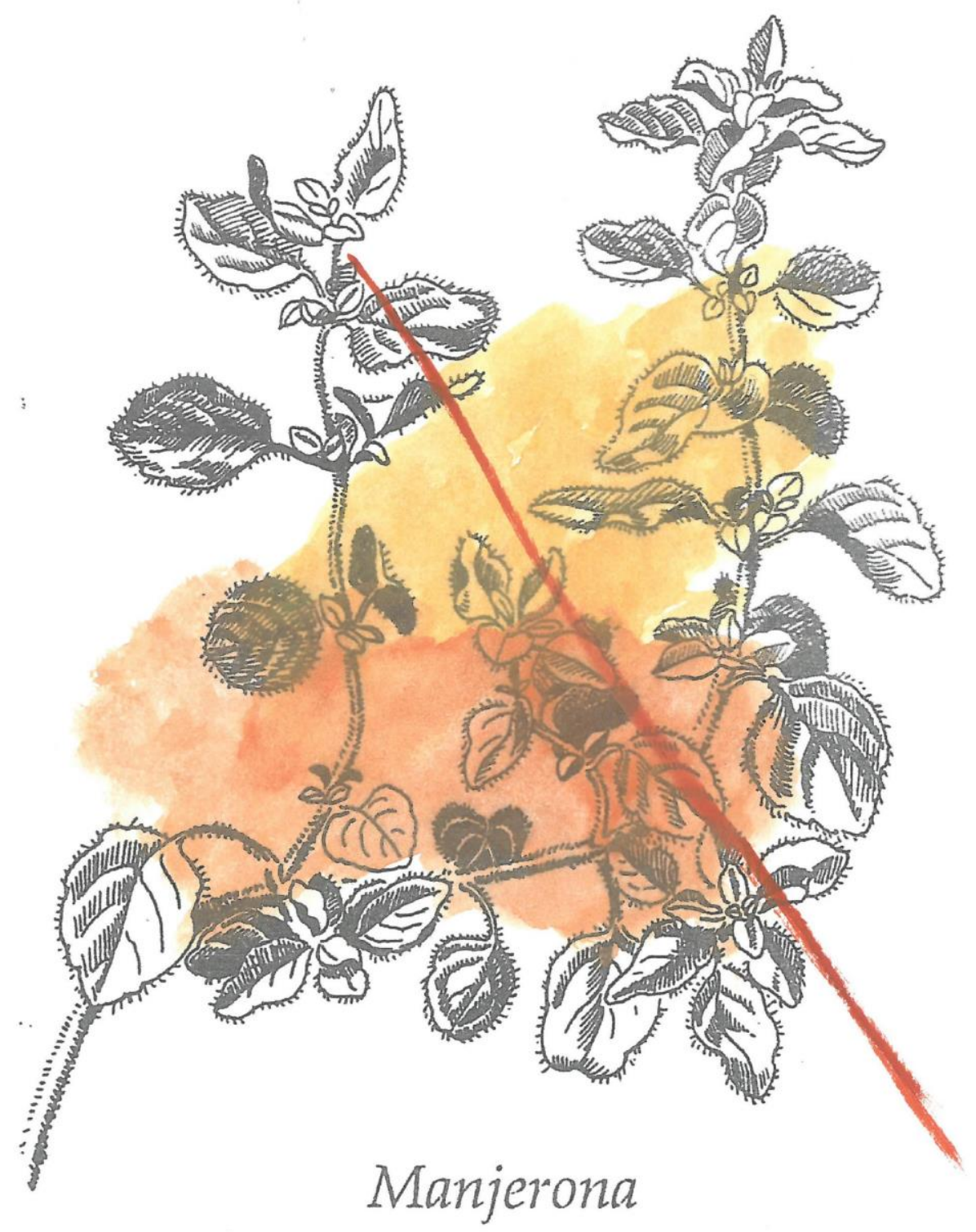

\section{Manjerona}

Foi num domingo, à tarde. No quintal de uma casa no Bom Retiro. Do portão de ferro ela avistava aquela que seria a condutora da experiência. Uma meia dúzia de gatos pingados sentados nas almofadas dispostas na grama.

Aquela mulher, saia longa, blusas soltas, um pano no cabelo comprido, fazendo uma tiara.

Ela pensou em ir embora, algumas vezes.

Um: - oi, pode entrar! Acabou com seu plano de fuga. 


\section{Verbena}

Parecia que a vó é que sabia das coisas. O vô, era meio bobo. Só conseguia se comunicar com piadas e anedotas. Acho que se tirasse o chapéu marrom da cabeça esquecia como é que se fala com gente.

A vó curava dor de barriga, dor no dente, cistite, verme, alergia, asma, bronquite, unha encravada, inflamação, bicho de pé, joelho ralado, artrite, artrose dor de amor

$$
\begin{aligned}
& \text { insônia } \\
& \text { Insônia } \\
& \text { Insônia } \\
& \text { Insônia } \\
& \text { Insônia } \\
& \text { Insônia }
\end{aligned}
$$

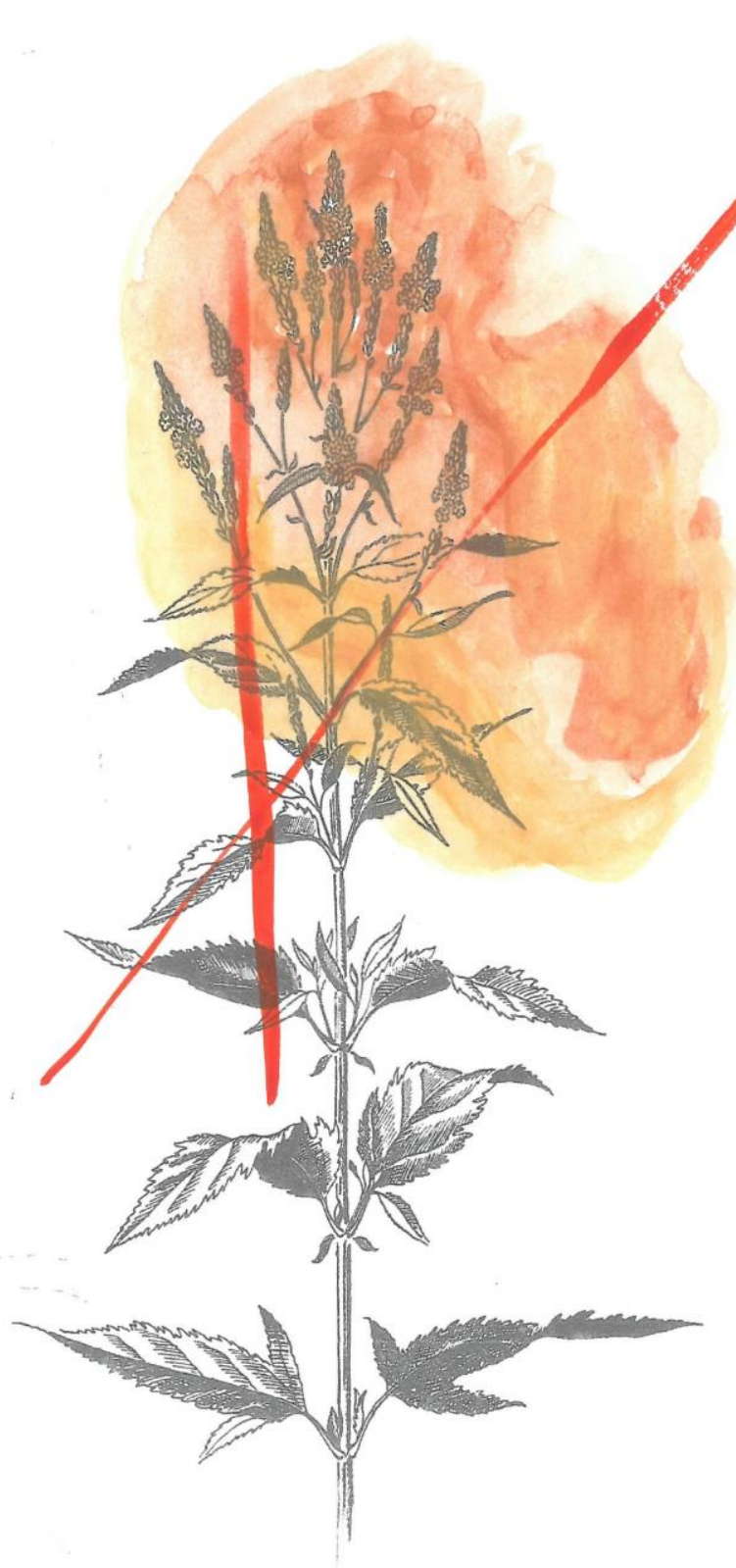

Verbena 


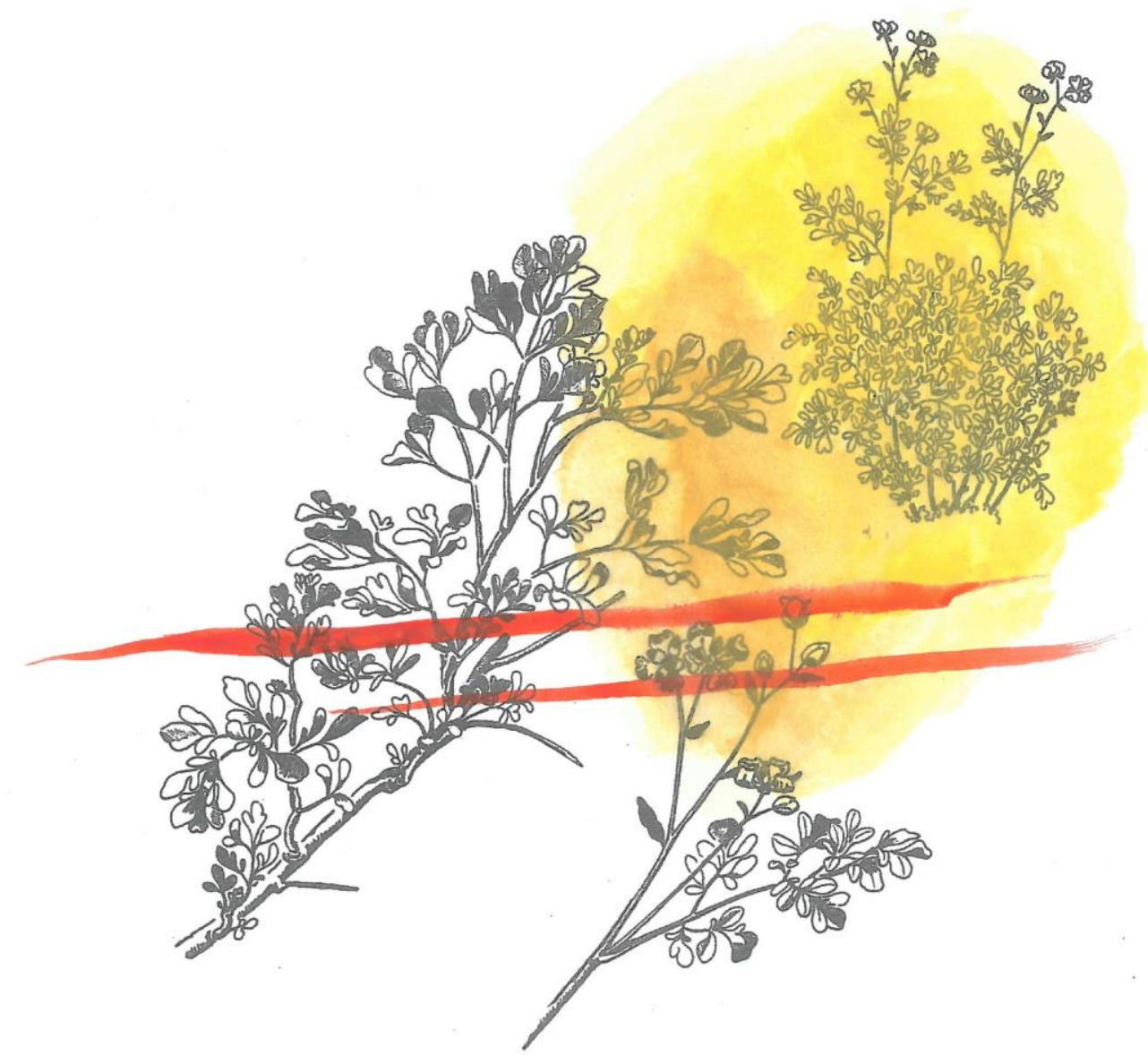

Arruda

\section{Arruda}

Era bem clichê, ela sabia. Mas ir encontrar o pequeno bosque ao lado da escola era a melhor rota de fuga. Cronometrava no relógio, 10 segundos antes de tocar o sinal.

\section{Corria}

E escondida no bosque imaginava feliz como seria ficar sem fazer nada ali até o meio dia. O silêncio era necessidade pra não ser apanhada e ela aprendeu a sussurrar com as plantas.

$11 \mathrm{~h} 59$,

fumava o último cigarro e seguia rua acima. 


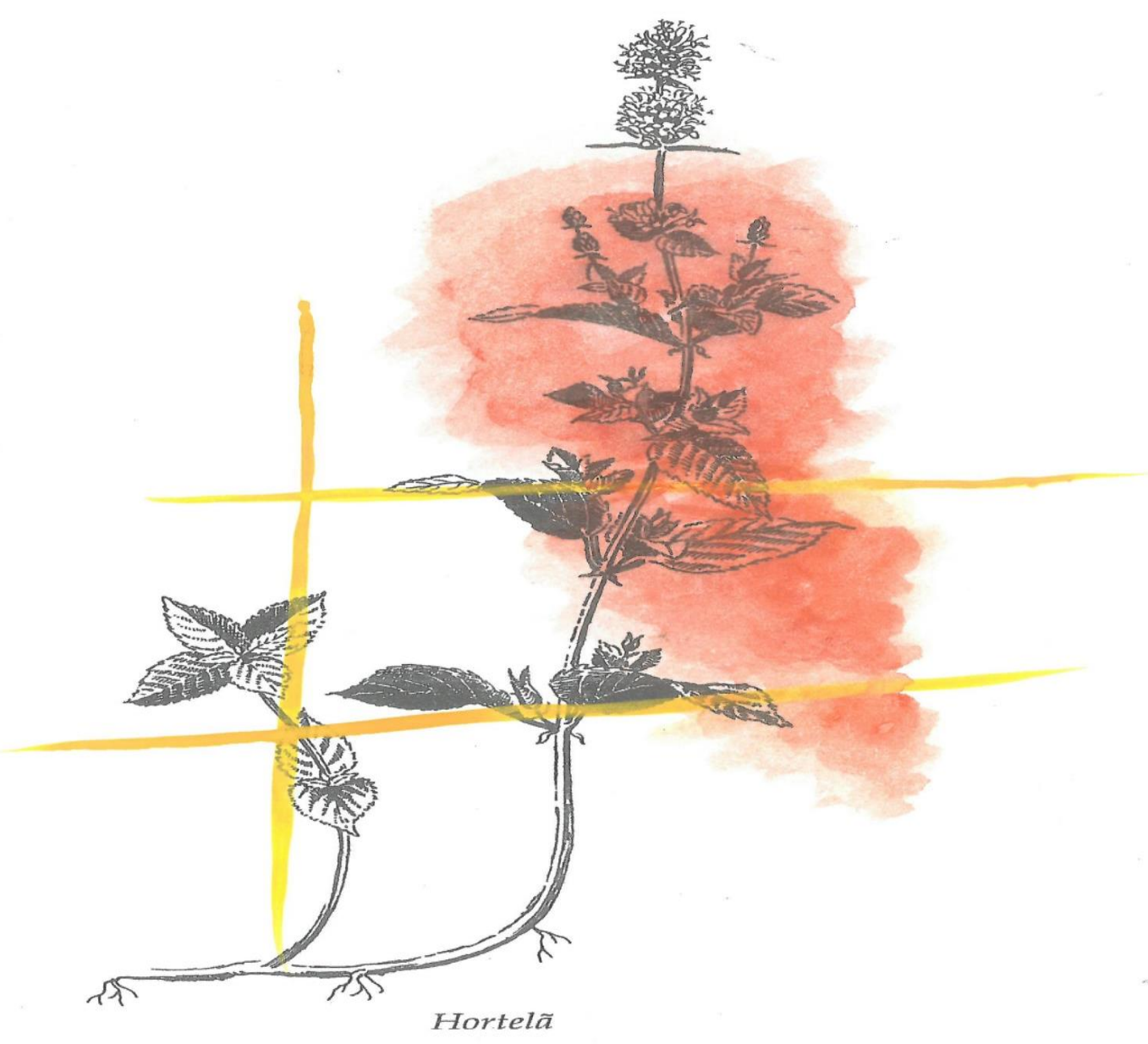

\section{Hortelã}

A onda

furiosa

estoura na pedra

- estardalhaço mineral -

Exausta

em vazante

revela

MARÉS

mais profundas 


\section{Referências}

COCCIA, Emanuele. A vida das plantas: uma metafísfica da mistura. Trad. Fernando Scheibe. Florianópolis: Cultura e Barbárie, 2018.

COCCIA, Emanuele. A virada vegetal. Trad. Felipe A. V. de Carli. São Paulo: N-1edições, 2018.

DELEUZE, Gilles; GUATTARI, Félix. Mil platôs: capitalismo e esquizofrenia, vol. 1. Trad. Aurélio G. Neto; Célia P. Costa. Rio de Janeiro: Editora 34, 1995.

DELEUZE, Gilles; GUATTARI, Félix. Mil platôs: capitalismo e esquizofrenia, vol. 3. Trad. Aurélio G. Neto; Célia P. Costa et al. São Paulo: Editora 34, 1996.

GUATTARI, Félix. As três ecologias. Trad. Maria Cristina F. Bittencourt, Campinas: Papirus, 1990.

GUATTARI, Félix. Caosmose um novo paradigma estético. Trad. Ana Lúcia de Oliveira; Lúcia C. Leão. São Paulo: Ed. 34, 1992.

LAPOUJADE, David. As existências mínimas. São Paulo: n-1edições, 2017.

MANCUSO, Stefano. Revolução das plantas: um novo modelo para o futuro. Trad. Regina Silva. São Paulo: Ubu Editora, 2019.

ROLNIK, Suely. Cartografia sentimental: transformações contemporâneas do desejo. 2. ed. Porto Alegre, Sulina: Ed. UFRGS, 2016.

ROLNIK, Suely. Esferas da insurreição: notas para uma vida não cafetinada. São Paulo: n1edições, 2018. 